\title{
@(1) \\ Oxidative stress in the bladder of men with LUTS undergoing open prostatectomy: a pilot study
}

Marcio Augusto Averbeck ${ }^{1,2,3}$, Nelson Gianni de Lima ${ }^{4}$, Gabriela Almeida Motta ${ }^{1}$, Lauro Beltrão ${ }^{2}$, Nury Jafar Abboud Filho ${ }^{2}$, Clarice Pereira Rigotti ${ }^{2}$, William Nascimento dos Santos ${ }^{2}$, Steven Kitzberger Jaeger dos Santos ${ }^{2}$, Luis Fernando Batista da Silva ${ }^{2}$, Ernani Luis Rhoden ${ }^{2,3,5}$

${ }^{1}$ Departamento Pós-graduação em Ciências da Saúde da Universidade Federal de Ciências da Saúde de Porto Alegre (UFCSPA), Porto Alegre, RS, Brasil; ${ }^{2}$ Serviço de Urologia, Complexo Hospitalar Santa Casa, Porto Alegre, RS, Brasil; ${ }^{3}$ Serviço de Urologia, Hospital Moinhos de Vento, Porto Alegre, RS, Brasil; ${ }^{4}$ Serviço de Urologia, Hospital de Nossa Senhora dos Navegantes, Torres, RS, Brasil; ${ }^{5}$ Disciplina de Urologia, Universidade Federal de Ciências da Saúde de Porto Alegre (UFCSPA), Porto Alegre, RS, Brasil

\section{ABSTRACT}

Purpose: This study aims to evaluate the link between preoperative parameters and oxidative stress (OS) markers in the bladder wall of men undergoing open prostatectomy.

Materials and Methods: From July 2014 to August 2016, men aged $\geq 50$ years and presenting with LUTS were prospectively enrolled. Preoperative assessment included validated questionnaires (IPSS and $\mathrm{OAB}$ - V8), lower urinary tract ultrasound and urodynamics. Bladder biopsies were taken during open prostatectomy for determination of OS markers. Increased OS was defined by increased concentration of malondialdehyde (MDA) and / or decreased concentration of antioxidant enzymes (superoxide dismutase and / or catalase). $\mathrm{P}<0.05$ was regarded as statistically significant.

Results: Thirty - eight consecutive patients were included. Mean age was $66.36 \pm 6.44$ years, mean prostate volume was $77.7 \pm 20.63 \mathrm{~cm} 3$, and mean IPSS was $11.05 \pm 8.72$ points. MDA concentration was increased in men with severe bladder outlet obstruction (B00 grade V - VI according to the Schaefer's nomogram) in comparison with BOO grade III - IV (p $=0.022$ ). Patients with severe LUTS also had higher MDA concentration when compared to those with mild LUTS ( $p=0.031$ ). There was a statistically significant association between increased post - void residual urine (cut off $\geq 50 \mathrm{~mL}$ ) and not only higher levels of MDA, but also reduced activity of SOD and catalase $(\mathrm{p}<0.05)$.

Conclusions: This pilot study showed that severity of LUTS and B00 were associated with increased MDA concentration in the bladder wall of men undergoing open prostatectomy. Further studies are still needed to assess the role of non - invasive biomarkers of OS in predicting bladder dysfunction in men with LUTS.

\section{ARTICLE INFO}

\section{Keywords:}

Urinary Bladder; Lower Urinary

Tract Symptoms; Urinary

Bladder Neck Obstruction;

Oxidative Stress

Int Braz J Urol. 2018; 44: 1182-93

\section{Submitted for publication:}

February 25, 2018

\section{Accepted after revision:}

August 12, 2018

Published as Ahead of Print:

September 20, 2018

\section{INTRODUCTION}

Current evidence suggests that bladder response to chronic obstruction occurs adaptively (1). Bladder functional changes caused by obstruction may be urodynamically classified in three main groups: (a) detrusor overactivity with or without reduced bladder compliance; (b) detrusor underactivity (DU) with impaired voiding; and (c) mixed pattern (2). 
Unfortunately, to date there is no reliable marker to predict which patients with bladder outlet obstruction (BO0) will inexorably present deterioration of bladder contractility, which, by itself, has been associated with poorer surgical outcomes in men with benign prostatic hyperplasia (BPH). Thomas et al. demonstrated the lack of long - term symptomatic or urodynamic gains from transurethral resection of the prostate (TURP) in men with both BPH and detrusor underactivity (3). On the other hand, persistent detrusor overactivity is also clinically relevant in patients undergoing prostate surgery, as it may impose increased risk of urgency urinary incontinence (4).

According to animal models, oxidative stress (OS) and bladder dysfunction (BD) may be related to ischemia - reperfusion process and $\mathrm{BOO}(5,6)$. Reactive oxygen species (ROS), including hydroxyl radicals, superoxide anions, and hydrogen peroxide, are normally produced in low levels during univalent reduction of oxygen to water and are important for diverse biological processes, including apoptosis, immunity, and cell defense against microorganisms (7). Increased formation of ROS and / or decreased antioxidant defense can be defined as OS, which may cause cell damage. Endogenous antioxidant enzymes such as superoxide dismutase (SOD) and catalase (CAT) are key to prevent damage from ROS. OS induces lipid peroxidation, which is expressed by formation of malondialdehyde (MDA) (8). Sezginer et al. has recently investigated the effects of different degrees of obstruction on bladder function in rats, showing that MDA levels were increased in severe partial B00 (9). Nevertheless, this association has not been properly assessed in humans so far.

Our study aims to evaluate the link between preoperative parameters (clinical, ultrasound and urodynamic findings) and OS markers in the bladder wall of men undergoing open prostate surgery. We hypothesized that severe bladder outlet obstruction was associated with increased OS in the bladder wall of men with lower urinary tract symptoms (LUTS).

\section{MATERIALS AND METHODS}

This was a pilot study, approved by the local Ethics Committee (approval number: 660.810).
From July 2014 to August 2016, men presenting with LUTS, aged $\geq 50$ years, prostate volume $\geq 40$ $\mathrm{mL}$, undergoing prostate surgery in a single university hospital were invited to take part in the study. The target population consisted of patients with BPH or organ - confined prostate cancer with concomitant LUTS in the perioperative period of open prostatectomy.

Our primary endpoint was the association between OS markers and severity of B00. Exploratory endpoints included the link between OS markers various preoperative characteristics, such as obesity, severity of LUTS, overactive bladder symptoms, ultrasound and urodynamic parameters.

Exclusion Criteria: Patients without complaint of one or more voiding LUTS over the last 3 months, previous pelvic surgery, neurological disease with secondary neurogenic lower urinary tract dysfunction, established cardiovascular disease (including prior stroke, myocardial ischemia and / or peripheral vascular disease) and patients relying on clean intermittent catheterization or taking drugs with potential effects on bladder function (e.g. anticholinergics and 5 - alpha - reductase inhibitors).

Patients who met the criteria for inclusion were invited to participate and received comprehensive information on further evaluations, which included lower urinary tract ultrasound, urodynamics and a bladder wall biopsy. Only those who were able to understand the risk - benefit profile of the assessments and provided written informed consent were included in the study. This study was carried out in accordance with the ethical standards of the responsible institutional committee and with the Helsinki Declaration.

\section{Clinical, laboratory and anthropometric assess- ments}

We collected clinical, and anthropometric data such as age, comorbidities, weight, height, body mass index (BMI), fasting glucose, and blood pressure. A single examiner performed the anthropometric measurements, in a standardized way (average of two or more measurements). Weight $(\mathrm{kg})$ was acquired using a precision balance and height was measured using a wall - mounted 
stadiometer. BMI was calculated as the ratio between weight $(\mathrm{kg})$ and height squared $\left(\mathrm{m}^{2}\right)$, and defined the following reference values: normal (18.5 - $\left.24.9 \mathrm{~kg} / \mathrm{m}^{2}\right)$, overweight (25.0 - $29.9 \mathrm{~kg} /$ $\mathrm{m}^{2}$ ), and obesity (30 kg / $\mathrm{m}^{2}$ or higher).

\section{LUTS assessment}

LUTS were assessed using the International Prostate Symptom Score (IPSS) (10). LUTS severity was classified as follows: mild (IPSS $\leq 7$ points), moderate (IPSS $\geq 8$ and $\leq 19$ points), and severe (IPSS $\geq 20$ points). The OAB - V8 questionnaire (Overactive Bladder - Validated 8 - question Screener) was also used to estimate the prevalence of overactive bladder symptoms, which were defined by a score $\geq 8$ points (11).

\section{Ultrasound assessment}

Ultrasound examination of the lower urinary tract was performed with the device Siemens Sonoline G50 ${ }^{\circledR}$ (Siemens AG, Munich, Germany). Total thickness of the bladder wall was measured by a mean of two sagittal measurements of the anterior bladder wall, with $250 \mathrm{~mL}$ of bladder filling $(12,13)$. Bladder wall thickness (BWT) was defined by the distance between the mucosa and the adventitia, both with hyperechogenic characteristics (14). Parameters such as prostate gland volume and intravesical prostatic protrusion (IPP) were also evaluated, according to the technique described by Yuen et al. (15). All measurements were performed transabdominally, by a single trained researcher using a high frequency transducer (7.5 $\mathrm{MHz}$ ). All ultrasound assessments were performed in the urodynamics unit, which allowed measurements with standardized bladder filling $(250 \mathrm{~mL})$.

\section{Urodynamic assessment}

Urodynamic studies were performed 2 to 3 weeks before open prostatectomy, using the Laborie Dorado $\mathrm{KT}^{\circledR}$ device (Laborie Medical, Ontario, Canada). All assessments were performed by a single trained researcher, in compliance with the International Continence Society (ICS) Good Urodynamic Practices (16). Post void residual (PVR) was defined as the volume of urine inside the bladder at the end of micturition (17). In our study, PVR was measured by catheterization after free uroflowmetry (before starting the filling cystometry). Increased PVR was arbitrarily defined as a volume $\geq 50 \mathrm{~mL}$ (18).

Bladder outlet obstruction (B00) was defined by the formula: detrusor pressure at maximum flow - (2x maximum flow). A value greater than 40 was regarded as B00, less than 20 as no obstruction, and between 20 and 40 as undetermined (19). The Schaefer's nomogram was used to assess B00 severity (19). Severe B00 was defined as zone V or VI on the nomogram. Detrusor underactivity was defined by the bladder contractility index (BCI), calculated by the formula: detrusor pressure at maximum flow + ( $5 \mathrm{x}$ maximum flow). Values under 100 were regarded as detrusor underactivity (19).

\section{Bladder biopsies}

A full - thickness fragment of the bladder wall measuring $1.0 \mathrm{~cm}^{2}$ was obtained from the anterior bladder wall during prostatectomy for determination of OS markers, including catalase, SOD and MDA. In order to aim at the detrusor muscle, each fragment had the mucosa and the perivesical fat removed, and then was frozen in liquid nitrogen at $-70^{\circ} \mathrm{C}$ in order to preserve the material for later analysis.

\section{Oxidative Stress Analysis}

Prior to performing OS analyzes, the bladder fragments were manually homogenized with $1.15 \%$ KPi buffer $(\mathrm{pH}=7.4)$ containing protease inhibitors, at a ratio of $5 \mathrm{~mL}$ buffer $(1.15 \% \mathrm{KCl})$ for each gram of tissue, and then the total protein concentrations of the bladder tissue were measured by the Bradford method (20) in a spectrophotometer at $535 \mathrm{~nm}$.

Thiobarbituric acid reactive substances test was performed by spectrophotometry at 535 $\mathrm{nm}$ to assess the concentration of MDA, which is a biomarker of peroxidative damage to lipids (21). Analysis of the activity of antioxidant enzyme SOD was performed by the pyrogallol autoxidation method (22), using spectrophotometry at $420 \mathrm{~nm}$. Determination of catalase activity, which is an antioxidant enzyme, was carried out by the 
rate of hydrogen peroxide $\left(\mathrm{H}_{2} \mathrm{O}_{2}\right)$ decomposition (spectrophotometry at $240 \mathrm{~nm}$ ) (23).

\section{Definition of increased oxidative stress}

Increased OS was defined by either of the following criteria: increased concentration of MDA and / or decreased concentration of antioxidant enzymes (SOD and / or catalase).

\section{Statistical analysis}

Data were expressed as mean \pm standard deviation. Results were compared using the Student t test, and controlled for the use of alpha blockers. Nominal variables were analyzed using the Fisher exact test. Bonferroni adjustment has been used for multiple testing correction. For specific parameters, such as prostate volume and BWT, distinct quartiles were taken to compare OS levels and define cutoffs. Statistical analyses were performed using SPSS $^{\circledR}$ version 22.0 for Windows (SPSS Inc., Chicago, IL, USA) and an alpha error inferior to $5 \%(p<0.05)$ was considered statistically significant.

\section{RESULTS}

Thirty - eight consecutive patients were included. Mean age was $66.36 \pm 6.44$ years. Mean body mass index (BMI) was $26.36 \pm 2.98 \mathrm{~kg} / \mathrm{m}^{2}$. The most common comorbidities were systemic arterial hypertension (50\%) and diabetes mellitus type 2 (DM2) (29\%). Regarding LUTS severity, 14 patients $(36.8 \%)$ presented mild symptoms, 18 (47.3\%) moderate and 6 (15.7\%) severe symptoms. Sixteen patients were taking alpha - blockers regularly in the last 6 months before surgery. Prevalence of overactive bladder symptoms (OAB - V8 score $\geq 8$ points) was $36.8 \%(\mathrm{n}=14)$. Baseline characteristics are described in Table- 1 .

Mean preoperative PSA was $8.17 \pm 3.55$ vs. $4.48 \pm 3.14 \mathrm{ng} / \mathrm{mL}$ in patients undergoing open radical prostatectomy $(n=34)$ and open retropubic prostatectomy $(\mathrm{n}=4)$, respectively $(\mathrm{p}=$ $0.16)$. There were no statistically significant differences in baseline characteristics between the two groups ( $p>0.05$ ). All 4 patients who underwent open simple suprapubic prostatectomy had patho- logical examination confirming BPH. All patients who underwent open radical prostatectomy had low - grade (Gleason $3+3$ or $3+4$ ) organ - confined prostate cancer and concomitant $\mathrm{BPH}$ in the pathological examination.

Mean prostate volume estimated by transabdominal ultrasound was $77.7 \pm 20.63 \mathrm{~cm}^{3}$. Mean bladder wall thickness (BWT) was $3.99 \pm$ $1.39 \mathrm{~mm}$. Seventeen patients (44.7\%) presented with intravesical protrusion of the median prostatic lobe, with a mean of $1.54 \pm 0.64 \mathrm{~cm}$.

In regards to urodynamics, 13 patients (34.2\%) had increased bladder sensation and 7 patients (18.4\%) presented reduced bladder sensation.

Table 1 - Baseline characteristics of men aged $\geq \mathbf{5 0}$ years with LUTS and undergoing open prostate surgery*.

\begin{tabular}{lc}
\hline & Mean \pm SD \\
\hline Clinical parameters & \\
Age (years) & $66.36 \pm 6.44$ \\
Weight (kilograms) & $77.71 \pm 8.07$ \\
BMI (kg/m²) & $26.36 \pm 2.98$ \\
IPSS score & $11.05 \pm 8.72$ \\
OAB-V8 score & $7.69 \pm 8.44$ \\
Ultrasound parameters & \\
Prostate volume & $77.7 \pm 20.63$ \\
IPP & $1.54 \pm 0.64$ \\
BWT & $3.99 \pm 1.39$ \\
Urodynamic parameters & \\
First desire (mL) & $195.62 \pm 78.57$ \\
Maximum cistometric capacity & $360.11 \pm 82.05$ \\
(mL) & \\
Compliance (mL/cmH 0 ) & $79.70 \pm 171.72$ \\
BOOI & $63.59 \pm 31.76$ \\
BCI & $108.64 \pm 27.33$ \\
\hline
\end{tabular}

${ }^{*} \mathbf{n}=38, \mathbf{z} \mathbf{n}=17$

$\mathbf{B M I}=$ Body mass index; $\mathbf{I P S S}=$ International Prostate Symptom Score; $\mathbf{O A B}-\mathbf{V} \mathbf{8}=$ Overactive Bladder-Validated 8-question Screener Questionnaire; IPP = Intravesical prostate protrusion; $\mathbf{B W T}=$ Bladder wall thickness; $\mathbf{B O O I}=$ Bladder outlet obstruction index; $\mathbf{B C I}=$ Bladder contractility index 
Twelve patients (31.6\%) had reduced bladder compliance and 7 patients (18.4\%) had reduced cystometric capacity. Detrusor overactivity was demonstrated in 11 patients (28.9\%) and urgency urinary incontinence in 5 (13.2\%). In the flow - pressure study, reduced peak urinary flow $(<15 \mathrm{~mL} / \mathrm{sec})$ was observed in 35 patients (92.1\%). Increased post - void residual urine (> $50 \mathrm{~mL}$ ) was observed in 22 patients (57.9\%). B00 was observed in 29 patients (76.3\%). Detrusor underactivity was present in 17 patients (44.7\%).

\section{Primary endpoint}

Severe BOO (zones V and VI on Schaefer's nomogram) was associated with increased MDA concentration in the bladder wall $(242.74 \pm 220.20$ vs. $114.90 \pm 54.08 \mathrm{pmoL} / \mathrm{mg} ; \mathrm{p}=0.022$ ) (Figure-1).

\section{Exploratory endpoints}

Concentration of OS markers (MDA, SOD, catalase) in the bladder wall according to preoperative parameters (clinical, ultrasound and urodynamic findings) are listed in Table- 2 .

Obesity was associated with reduced activity of the antioxidant enzyme catalase (170.88 \pm 27.46 vs. $317.11 \pm 268.98 \mathrm{pmoL} / \mathrm{mg}$ in obese and in non - obese patients, respectively; $p=0.01$ ) and with reduced activity of the antioxidant enzyme SOD $(0.4 \pm 0.19$ vs. $0.76 \pm 0.59$ Usod / $\mathrm{mg}$ in obese and in non - obese patients, respectively; $p=0.05$ ).

Patients with severe LUTS (IPSS score $\geq$ 20 points) had higher MDA concentration in the bladder wall when compared to the patients with mild LUTS (IPSS $<8$ points): $290.93 \pm 237.87$ vs. $111.93 \pm 82.37 \mathrm{pmoL} / \mathrm{mg}$, respectively $(\mathrm{p}=$ 0.031 ). Patients with moderate LUTS (IPSS $\geq 8$ and $<20$ points) had a mean of MDA concentration of $144.85 \pm 112.88 \mathrm{pmoL} / \mathrm{mg}$ (intermediate values in - between mild and severe LUTS outcomes, but not statistically significant in the multivariate analysis). Likewise, the diagnosis of $\mathrm{OAB}$ (OAB V8 score $\geq 8$ points) had no association with increased OS in the bladder wall ( $p>0.05)$.

MDA concentration was higher in patients with BWT $\geq 3 \mathrm{~mm}$ compared to those with BWT <

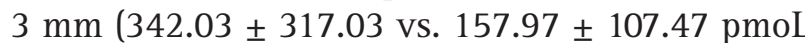
/ $\mathrm{mg}$, respectively; $\mathrm{p}=0.015)$. Increased prostate volume (PV) was associated with higher concentrations of MDA: $236.43 \pm 217.75$ vs. $130.33 \pm$ $66.44 \mathrm{pmoL} / \mathrm{mg}$ in patients with $\mathrm{PV} \geq 80 \mathrm{~cm} 3$ and PV $<80 \mathrm{~cm} 3$, respectively $(\mathrm{p}=0.048)$. However, IPP was not associated with increased OS in the bladder wall $(p>0.05)$.

Figure 1 - Severity of bladder outlet obstruction according to the Schaefer's nomogram (Zones V-VI versus III-IV) and MDA concentration in the bladder wall of men aged $\geq \mathbf{5 0}$ years, presenting with LUTS and undergoing open prostatectomy $(n=29)^{*}$.

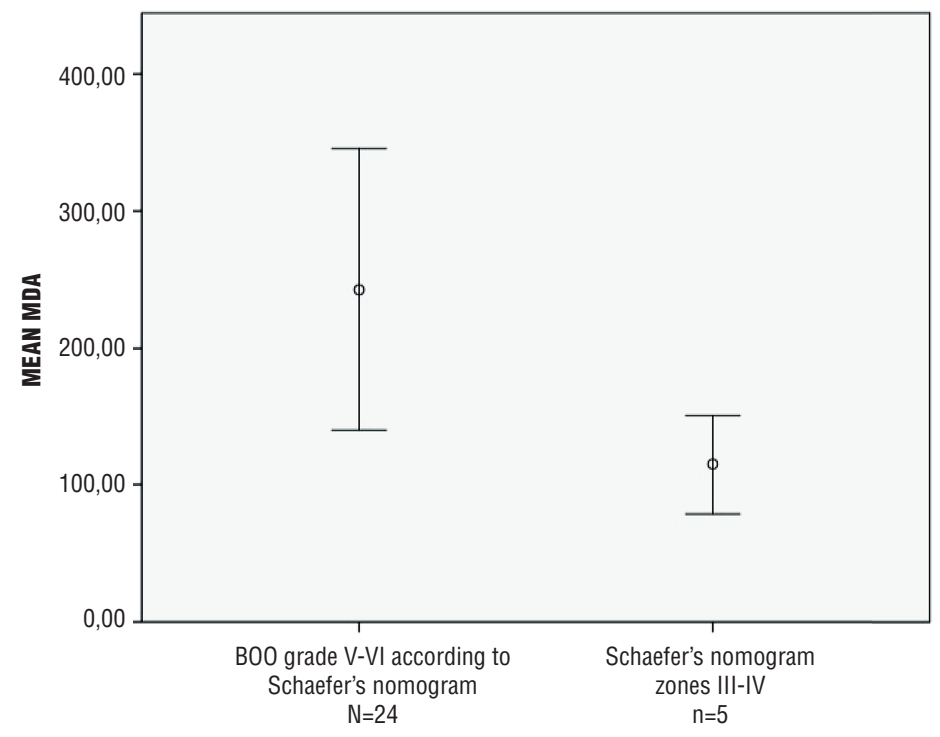

MDA = malondialdehyde; LUTS $=$ lower urinary tract symptoms

${ }^{*} \mathbf{p}=0.022$ 
Table 2 - Clinical, ultrasound and urodynamic parameters versus oxidative stress markers (MDA, SOD, catalase) in the bladder wall of men aged $\geq \mathbf{5 0}$ years with LUTS and undergoing open prostate surgery*.

\begin{tabular}{|c|c|c|c|}
\hline \multirow[t]{4}{*}{ Preoperative parameters } & \multicolumn{3}{|c|}{ Oxidative stress markers (Mean \pm SD; $p$ value ${ }^{v}$ ) } \\
\hline & MDA concentration & SOD activity & Catalase activity \\
\hline & (pro-oxidant) & (antioxidant enzyme) & (antioxidant enzyme) \\
\hline & $\mathrm{pmoL} / \mathrm{mg}$ & Usod / mg & $\mathrm{pmoL} / \mathrm{mg}$ \\
\hline \multicolumn{4}{|l|}{ Clinical } \\
\hline \multicolumn{4}{|l|}{ Obesity (BMI $\left.\geq 30 \mathrm{~kg} / \mathrm{m}^{2}\right)$} \\
\hline Yes $(n=4)$ & $216.41 \pm 199.62$ & $0.4 \pm 0.19$ & $170.88 \pm 27.46$ \\
\hline \multirow[t]{2}{*}{ No $(n=34)$} & $120.97 \pm 101.70$ & $0.76 \pm 0.59$ & $317.11 \pm 268.98$ \\
\hline & $p=0.38$ & $p=0.05$ & $p=0.01$ \\
\hline \multicolumn{4}{|l|}{ LUTS severity } \\
\hline IPSS $\geq 20$ points $(n=6)$ & $290.93 \pm 237.87$ & $0.69 \pm 0.56$ & $181.81 \pm 48.59$ \\
\hline \multirow[t]{2}{*}{ IPSS $<8$ points $(n=14)$} & $111.93 \pm 82.37$ & $0.71 \pm 0.95$ & $327.06 \pm 215.17$ \\
\hline & $p=0.031$ & $p=0.48$ & $p=0.68$ \\
\hline \multicolumn{4}{|l|}{ Overactive bladder symptoms } \\
\hline OAB-V8 $\geq 8$ points $(n=14)$ & $158.16 \pm 133.98$ & $0.62 \pm 0.39$ & $314.37 \pm 354.72$ \\
\hline \multirow[t]{2}{*}{ OAB-V8 $<8$ points $(n=24)$} & $217.88 \pm 211.43$ & $0.74 \pm 0.63$ & $281.83 \pm 138.66$ \\
\hline & $p=0.33$ & $p=0.46$ & $p=0.74$ \\
\hline \multicolumn{4}{|l|}{ Ultrasound } \\
\hline \multicolumn{4}{|l|}{ Bladder Wall Thickness } \\
\hline$\geq 3 \mathrm{~mm}(\mathrm{n}=30)$ & $342.03 \pm 317.03$ & $0.59 \pm 0.35$ & $262.15 \pm 143.57$ \\
\hline \multirow[t]{2}{*}{$<3 \mathrm{~mm}(\mathrm{n}=8)$} & $157.97 \pm 107.47$ & $0.69 \pm 057$ & $283.47 \pm 125.18$ \\
\hline & $p=0.015$ & $p=0.53$ & $p=0.7$ \\
\hline \multicolumn{4}{|l|}{ Prostate volume } \\
\hline$\geq 80 \mathrm{~cm}^{3}(\mathrm{n}=13)$ & $236.43 \pm 217.75$ & $0.54 \pm 0,31$ & $259.69 \pm 102.19$ \\
\hline \multirow[t]{2}{*}{$<80 \mathrm{~cm}^{3}(\mathrm{n}=25)$} & $130.33 \pm 66.44$ & $0.75 \pm 0.61$ & $269.70 \pm 157.18$ \\
\hline & $p=0.048$ & $p=0.18$ & $p=0.81$ \\
\hline \multicolumn{4}{|l|}{ IPP } \\
\hline \multirow{3}{*}{ No $(n=21)$} & 248.74 & $0.51 \pm 0.29$ & $261.38 \pm 125.29$ \\
\hline & 136.37 & $0.81 \pm 0.65$ & $270.27 \pm 152.60$ \\
\hline & $p=0.064$ & $p=0.095$ & $p=0.84$ \\
\hline \multicolumn{4}{|l|}{ Urodynamics } \\
\hline \multicolumn{4}{|l|}{ Reduced bladder sensation } \\
\hline Yes $(n=7)$ & $202.90 \pm 192.37$ & $0.7 \pm 0.4$ & $205.66 \pm 60.21$ \\
\hline \multirow[t]{2}{*}{ No $(n=31)$} & $155.06 \pm 106.91$ & $0.67 \pm 0.56$ & $280.30 \pm 148.67$ \\
\hline & $p=0.44$ & $p=0.85$ & $p=0.045$ \\
\hline Urgency $^{\S}$ & & & \\
\hline Yes $(n=13)$ & $250.35 \pm 245.70$ & $0.62 \pm 0.44$ & $245.68 \pm 130.89$ \\
\hline No $(n=25)$ & $166.14 \pm 133.19$ & $0.76 \pm 0.68$ & $304.03 \pm 150.45$ \\
\hline & $p=0.28$ & $p=0.51$ & $p=0.25$ \\
\hline Detrusor overactivity & & & \\
\hline Yes $(n=11)$ & $198.57 \pm 206.02$ & $0.65 \pm 0.43$ & $262.84 \pm 125.15$ \\
\hline No $(n=27)$ & $194.73 \pm 175.64$ & $0.73 \pm 0.74$ & $267.60 \pm 146.64$ \\
\hline & $p=0.96$ & $p=0.73$ & $p=0.92$ \\
\hline Severity of bladder outlet obstruct & & & \\
\hline according to the Schäfer nomogra & & & \\
\hline Zones $\mathrm{V}$ and $\mathrm{VI}(\mathrm{n}=24)$ & $242.74 \pm 220.20$ & $0.53 \pm 0.29$ & $227.75 \pm 65.1$ \\
\hline Zones III-IV $(n=5)$ & $114.90 \pm 54.08$ & $0.78 \pm 0.64$ & $288.89 \pm 159.75$ \\
\hline & $p=0.022$ & $p=0.12$ & $p=0.13$ \\
\hline Detrusor underactivity & & & \\
\hline Yes $(B C I<100)(n=17)$ & $222.90 \pm 241.21$ & $0.55 \pm 0.36$ & $237.39 \pm 120.64$ \\
\hline No $(B C I \geq 100)(n=21)$ & $171.83 \pm 107.60$ & $0.77 \pm 0.63$ & $290.66 \pm 151.38$ \\
\hline & $p=0.44$ & $p=0.19$ & $p=0.24$ \\
\hline Post-void residual urine & & & \\
\hline$\geq 50 \mathrm{~mL}(\mathrm{n}=22)$ & $270 \pm 197.06$ & $0.48 \pm 0.29$ & $212.71 \pm 99.32$ \\
\hline$<50 \mathrm{~mL}(\mathrm{n}=16)$ & $143.96 \pm 154.91$ & $0.97 \pm 0.67$ & $344.61 \pm 154.01$ \\
\hline & $p=0.045$ & $p=0.005$ & $p=0.003$ \\
\hline
\end{tabular}

MDA = malondialdehyde; $\mathbf{S O D}=$ superoxide dismutase; $\mathbf{L U T S}=$ lower urinary tract symptoms; $\mathbf{S D}=$ standard deviation; $\mathbf{B M I}$ = body mass index; IPSS = International Prostate Symptom Score; OAB-V8 = Overactive Bladder-Validated 8-question Screener Questionnaire; IPP = intravesical protrusion of the median prostatic lobe; $\mathbf{B C I}=$ bladder contractility index; ${ }^{*} \mathbf{n}=38 ; \mathbf{Z}=\mathrm{T}$ test; $\mathbf{8}$ "urgency" was defined as "the complaint of a sudden compelling desire to pass urine which is difficult to defer" (18); १ primary endpoint 
Regarding urodynamic parameters, it has been shown that patients with reduced bladder sensation had a statistically significant reduction of the activity of the catalase enzyme in the bladder wall when compared to those patients with normal bladder sensation $(205.66 \pm 60.21$ vs. $280.30 \pm 148.67$ pmoL / mg, respectively; $\mathrm{p}=0.045$ ). On the other hand, parameters such as urinary urgency, detrusor overactivity, reduced bladder compliance or cystometric capacity, and weak stream were not associated with increased OS in the bladder wall ( $p>0.05)$.

Increased MDA concentration and reduced activity of antioxidant enzymes (both catalase and SOD) were observed in the bladder wall of patients with post - void residual urine (PVR) $\geq 50 \mathrm{~mL}$ :

MDA: $270 \pm 197.06$ vs. $143.96 \pm 154.91 \mathrm{pmoL}$ / mg; p $=0.045$ (Figure-2a),

SOD: $0.48 \pm 0.29$ vs. $0.97 \pm 0.67$ Usod / mg; $\mathrm{p}=0.005$ (Figure-2b),

Catalase: $212.71 \pm 99.32$ vs. $344.61 \pm 154.01$ pmoL / mg; $\mathrm{p}=0.003$ (Figure-2c).

\section{DISCUSSION}

To our knowledge, this is the first study investigating OS markers (MDA, SOD and catalase) in the detrusor muscle of humans undergoing open prostate surgery. Clinical factors (LUTS severity and obesity, ultrasound findings (bladder wall thickness $\geq 3 \mathrm{~mm}$, prostate volume $\geq 80 \mathrm{~cm} 3$ ), and urodynamic parameters (BOO severity, post - void residual urine $\geq 50 \mathrm{~mL}$ ) were associated with either increased MDA concentration or reduced activity of antioxidant enzymes (SOD / catalase) in the bladder wall. Identification of such factors may have clinical relevance, as evidence from animal models suggested a relationship between increased OS and bladder dysfunction (24-26).

Generation of reactive oxygen species (ROS) and ischemia - reperfusion injury have been proposed as the primary etiological factors in obstruction - induced bladder dysfunction (9). At a molecular level, reactive oxygen species exhibit signaling and cell - function - modifying roles (27). OS occurs when the net flux of reactive oxygen species (ROS) and reactive nitrogen species (RNS) production exceeds the capacity of the cell to detoxify these potentially injurious oxidants. Functional in vitro studies showed that elevated ROS levels impair bladder contractile responses $(28,29)$.

Several biomarkers have been used in experimental models to assess both urinary and plasma OS, including 8 - hydroxy - 2' - deoxyguanosine (8 OHdG), MDA, total anti - oxidant capacity (TAC) and glutathione (GSH) (30). SOD and catalase assays have also been carried out on animal tissues to study the effects of partial BOO on the cell's anti - oxidant defense mechanisms (25). In our pilot study, OS biomarkers included MDA, catalase and SOD. Experimental studies showed that both the SOD and catalase activities are calcium - sensitive and changes in their activity would be expected to occur during ischemia, which can result in decreased antioxidant capacity of the bladder smooth muscle and mucosa (31). Hence, there sensitivity and specificity issues related to distinct OS biomarkers and caution should be exercised in interpreting the results of such studies.

There is growing interest on the association between LUTS and systemic conditions such as obesity, diabetes mellitus and metabolic syndrome in men $(32,33)$. Dibello et al. (33) compared the prevalence of metabolic syndrome in men aged $\geq 50$ years with and without a diagnosis of BPH from a large database (UK Clinical Practice Research Datalink - CPRD). Among men with BPH, 26.5\% ( $\mathrm{n}=85.103)$ had diagnosis of metabolic syndrome, compared with 20.9\% without BPH (control group, $\mathrm{n}=85.103$ ) (absolute difference of 5.6\%, p < 0.001). In our pilot study, data on height and weight of the patients were recorded and allowed the calculation of BMI. Patients with BMI $\geq 30(n=4)$ presented with higher levels of both antioxidant enzymes catalase and SOD in the bladder wall in comparison with those with BMI $<30$ ( $\mathrm{n}=$ 34).

Non - invasive assessment of PVR is usually recommended as a first - line diagnostic tool in men with LUTS (34). Despite the lack of a consensual cutoff, it is known that increased PVR may represent a risk factor for acute urinary retention and / or bladder dysfunction among these patients (35). According to Crawford et al., who studied a total of 3.047 men with BPH over 4.5 years, a baseline PVR of $39 \mathrm{~mL}$ or greater was an independent predictor of BPH clinical progression in patients not receiving active treatment for LUTS (36). Our study showed that a PVR $\geq 50 \mathrm{~mL}$ was associated with increased OS in 
Figure 2a - Increased MDA concentration in the bladder wall of men aged $\geq \mathbf{5 0}$ years, undergoing open prostatectomy and presenting with LUTS and PVR $\geq 50 \mathrm{~mL}(\mathrm{n}=\mathbf{3 8})^{*}$

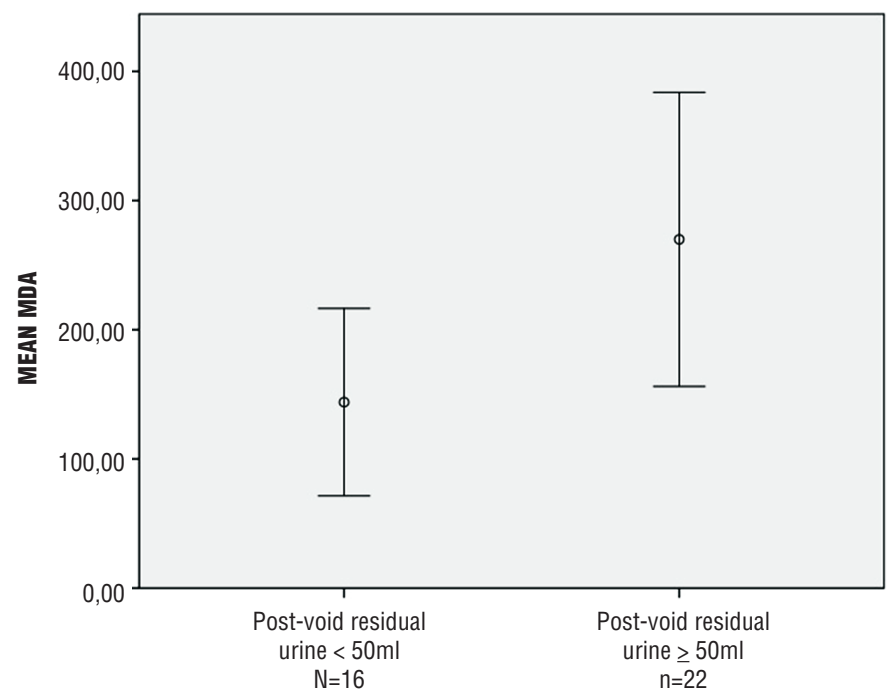

MDA = malondialdehyde; LUTS = lower urinary tract symptoms; PVR = post-void residual urine

${ }^{*} \mathrm{p}=0.045$

Figure $\mathbf{2 b}$ - Decreased activity of the antioxidant enzyme SOD in the bladder wall of men aged $\geq \mathbf{5 0}$ years, undergoing open prostatectomy and presenting with LUTS and PVR $\geq 50 \mathrm{~mL}(\mathrm{n}=38)^{*}$

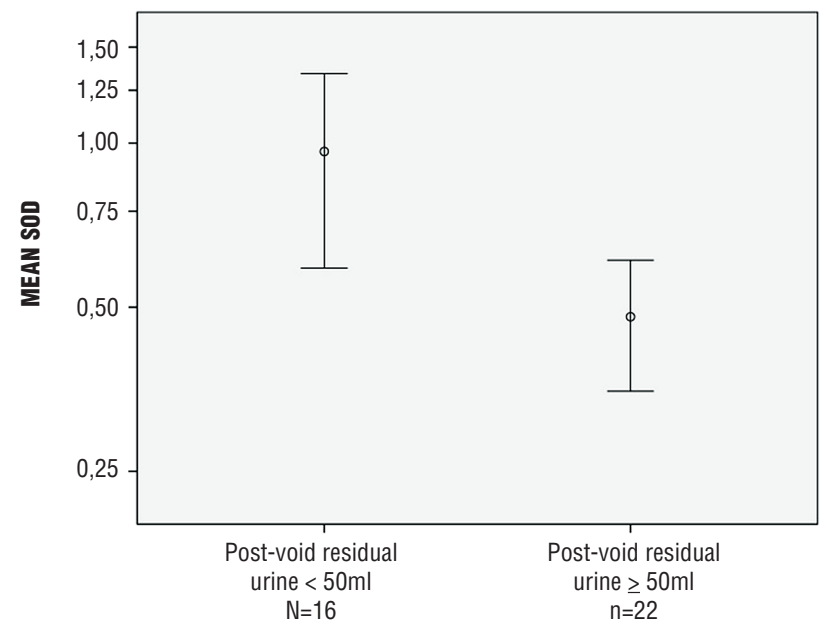

SOD = superoxide dismutase; LUTS = lower urinary tract symptoms; PVR = post-void residual urine

${ }^{*} \mathrm{p}=0.005$ 
Figure 2c. Decreased activity of the antioxidant enzyme catalase in the bladder wall of men aged $\geq \mathbf{5 0}$ years, undergoing open prostatectomy and presenting with LUTS and PVR $\geq 50 \mathrm{~mL}(\mathrm{n}=38)^{*}$

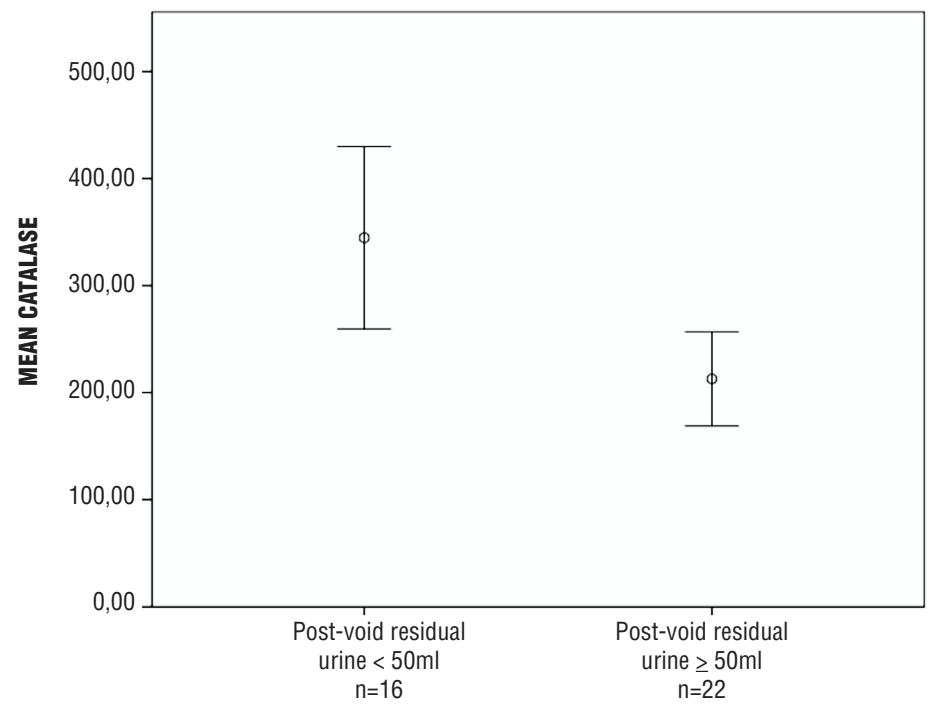

LUTS = lower urinary tract symptoms; PVR = post-void residual urine

${ }^{*} p=0.003$

the bladder wall (higher MDA concentration; reduced activity of both catalase and SOD).

Although not recommended in the routine assessment of LUTS in men without neurological diseases, urodynamics may be important for selected patients in order to define the pattern of voiding dysfunction (34). Incomplete bladder emptying may be caused by detrusor underactivity (DU), bladder outlet obstruction (B00), or dysfunctional voiding $(17,37)$. Previous studies showed DU in up to $40 \%$ of men aged $>65$ years and even up to $48 \%$ of men aged $\geq$ 70 years $(38,39)$. Despite being a prevalent condition in the elderly population, the origin of DU in men without neurological diseases remains controversial (40). BOO and increased OS have been related to a higher risk of detrusor underactivity in animal models $(25,41,42)$. Callaghan et al. demonstrated that partial BOO has significant effects on the activity of both SOD and catalase in the bladder, with variations that are dependent on the severity and duration of the obstruction (25). Our study demonstrated that patients with severe LUTS (IPSS $\geq 20$ points; $n=6$ ) and severe BOO (grade V - VI in Schaefer's nomogram; $n$ = 24) had increased MDA concentration in the bladder wall in comparison with patients with mild LUTS
(IPSS $<8$ points; $\mathrm{n}=14$ ) and B00 grade III - IV ( $\mathrm{n}=$ 5), respectively. These findings may be clinically relevant, as bladder dysfunction has been implicated as a risk factor for persistent LUTS after prostate surgery (2).

Other non - invasive tests, such as ultrasound measurement of IPP, detrusor wall thickness (DWT) or bladder wall thickness (BWT) have been advocated to predict the chances of BOO in the male population $(12,37)$. Increased DWT is observed in adult men with non - neurogenic LUTS and BOO (12). A prospective study demonstrated that DWT $\geq 2 \mathrm{~mm}$ in bladders filled $\geq 250 \mathrm{~mL}$ was a predictor of B00 (43). Additionally, Güzel et al. have studied the utility of BWT in men with HPB / LUTS and demonstrated that this parameter is an easy, quick, and repeatable test to predict B0O severity (44). Most probably, due to the high proportion of patients with BOO in our study, we could not demonstrate an association between BWT and obstruction. On the other hand, BWT $\geq 3$ $\mathrm{mm}$ was associated with increased OS in the bladder wall $(\mathrm{p}=0.015)$.

The main limitation of our pilot study is the small number of patients included. Since the introduction of 5 - alpha - reductase inhibitors in the cli- 
nical practice, the number of patients who require open prostate surgery for BPH has dropped significantly (45). On the other hand, BPH and prostate cancer (PCa) are often coexisting in older men (46). Böcking et al. (47) demonstrated that latent prostate cancer would be present in more than 50\% of men over the age of 80 . In our study, most of the patients underwent open radical prostatectomy ( $\mathrm{n}=34$ ); notwithstanding, all of them had been followed up at the urology outpatient clinic of the same institution due to BPH symptoms prior to the diagnosis of prostate cancer. In addition, all patients who underwent open radical prostatectomy had low - grade (Gleason $3+3$ or $3+4$ ) organ confined prostate cancer and concomitant $\mathrm{BPH}$ in the pathological examination. Another limitation of our study was the lack of OS analysis in the urothelial layer of the bladder samples. Evidence from animal models suggests that the urothelium is also sensitive to oxidative stress generated by partial obstruction (48). However, as per protocol, our study was aimed at assessing the oxidative stress in the smooth muscle layer (detrusor). In addition, despite the use of previously validated assessment procedures, there is no perfect method for assessing tissue OS. To counteract oxidative and nitrosative stress, human cells employ complex defense mechanisms (27). The interpretation of all OS studies should be done in the light of such imperfection, since there are distinct cellular enzymatic and non - enzymatic antioxidative pathways. At last, the invasiveness of bladder biopsies may also be seen as a limitation. Future research should focus on non - invasive techniques and biomarkers to assess the oxidative stress in the human bladder.

Despite inherent limitations, our pilot study has several strengths. Firstly, our restricted inclusion criteria aimed at patients with higher risk of BOO (76.3\% of our study population). Secondly, the technique for retrieving bladder biopsies in our protocol did not require electrocautery and favored the OS analysis. Thirdly, ultrasound and urodynamic assessments were standardized and performed by a single trained researcher, who was blind to the OS analysis and results.

\section{CONCLUSIONS}

This pilot study revealed increased MDA concentration in the bladder wall of men with severe LUTS (IPSS score $\geq 20$ points), severe B00 (Schaefer's nomogram grade V - VI), BWT $\geq 3 \mathrm{~mm}$ and PV $\geq$ $80 \mathrm{~cm} 3$. Reduced activity of the antioxidant enzymes (catalase and / or SOD) was demonstrated in patients with $\mathrm{BMI} \geq 30$ and in those with reduced bladder sensation on filling cystometry. Increased PVR $(\geq 50$ $\mathrm{mL}$ ) was associated with both increased MDA concentration and reduced activity of antioxidant enzymes (catalase and SOD) in the bladder wall.

Novel diagnostic methods targeting oxidative and / or inflammatory pathways may be a reasonable strategy for a more comprehensive evaluation of patients presenting with severe LUTS and B00. Further studies are still needed to assess the role of non - invasive biomarkers of OS in predicting bladder dysfunction in men with LUTS.

\section{CONFLICTS OF INTEREST}

Doctor Márcio Augusto Averbeck reports grants and personal fees from Medtronic, Coloplast, and GSK outside the submitted work.

All the other authors do not have any conflict of interest, including specific financial interests or relationships and affiliations relevant to the subject matter or materials discussed in the manuscript.

\section{REFERENCES}

1. Metcalfe PD, Wang J, Jiao H, Huang $Y$, Hori K, Moore $\mathrm{RB}$, et al. Bladder outlet obstruction: progression from inflammation to fibrosis. BJU Int. 2010;106:1686-94.

2. Thomas AW, Cannon A, Bartlett E, Ellis-Jones J, Abrams P. The natural history of lower urinary tract dysfunction in men: minimum 10-year urodynamic followup of transurethral resection of prostate for bladder outlet obstruction. J Urol. 2005;174:1887-91.

3. Thomas AW, Cannon A, Bartlett E, Ellis-Jones J, Abrams P. The natural history of lower urinary tract dysfunction in men: the influence of detrusor underactivity on the outcome after transurethral resection of the prostate with a minimum 10year urodynamic follow-up. BJU Int. 2004;93:745-50. 
4. Kageyama S, Watanabe T, Kurita Y, Ushiyama T, Suzuki K, Fujita K. Can persisting detrusor hyperreflexia be predicted after transurethral prostatectomy for benign prostatic hypertrophy? Neurourol Urodyn. 2000;19:233-40.

5. Goi Y, Tomiyama Y, Maruyama I, Tatemichi S, Maruyama K, Kobayashi M, et al. Silodosin, an a $(1 \mathrm{~A})$-Adrenoceptor Antagonist, May Ameliorate Ischemia-Induced Bladder Denervation and Detrusor Dysfunction by Improving Bladder Blood Flow. Pharmacology. 2016;97:161-70.

6. Nomiya M, Yamaguchi O, Andersson KE, Sagawa K, Aikawa $\mathrm{K}$, Shishido K, et al. The effect of atherosclerosis-induced chronic bladder ischemia on bladder function in the rat. Neurourol Urodyn. 2012;31:195-200.

7. Kurutas EB, Ciragil P, Gul M, Kilinc M. The effects of oxidative stress in urinary tract infection. Mediators Inflamm. 2005;2005:242-4.

8. Matés JM, Pérez-Gómez C, Núñez de Castro I. Antioxidant enzymes and human diseases. Clin Biochem. 1999;32:595603.

9. Sezginer EK, Yilmaz-Oral D, Lokman U, Nebioglu S, Aktan F, Gur S. Effects of varying degrees of partial bladder outlet obstruction on urinary bladder function of rats: A novel link to inflammation, oxidative stress and hypoxia. Low Urin Tract Symptoms. 2017. [Epub ahead of print]

10. Rodrigues Netto N Jr, de Lima ML, de Andrade EF, Apuzzo F, da Silva MB, Davidzon IM, et al. Latin American study on patient acceptance of the International Prostate Symptom Score (IPSS) in the evaluation of symptomatic benign prostatic hyperplasia. Urology. 1997;49:46-9.

11. Acquadro C, Kopp Z, Coyne KS, Corcos J, Tubaro A, Choo MS, et al. Translating overactive bladder questionnaires in 14 languages. Urology. 2006;67:536-40. Erratum in: Urology. 2007;69:202.

12. Oelke M, Höfner K, Jonas U, Ubbink D, de la Rosette J, Wijkstra $H$. Ultrasound measurement of detrusor wall thickness in healthy adults. Neurourol Urodyn. 2006;25:30817; discussion 318.

13. Oelke M. International Consultation on IncontinenceResearch Society (ICl-RS) report on non-invasive urodynamics: the need of standardization of ultrasound bladder and detrusor wall thickness measurements to quantify bladder wall hypertrophy. Neurourol Urodyn. 2010;29:634-9.

14. Manieri C, Carter SS, Romano G, Trucchi A, Valenti M, Tubaro $A$. The diagnosis of bladder outlet obstruction in men by ultrasound measurement of bladder wall thickness. J Urol. 1998;159:761-5.
15. Yuen JS, Ngiap JT, Cheng CW, Foo KT. Effects of bladder volume on transabdominal ultrasound measurements of intravesical prostatic protrusion and volume. Int J Urol. 2002;9:225-9.

16. Rosier PFWM, Schaefer W, Lose G, Goldman HB, Guralnick M, Eustice S, et al. International Continence Society Good Urodynamic Practices and Terms 2016: Urodynamics, uroflowmetry, cystometry, and pressure-flow study. Neurourol Urodyn. 2017;36:1243-60.

17. Abrams P, Cardozo L, Fall M, Griffiths D, Rosier P, Ulmsten $U$, et al. The standardisation of terminology of lower urinary tract function: report from the Standardisation Sub-committee of the International Continence Society. Neurourol Urodyn. 2002;21:167-78.

18. Ko YH, Chae JY, Jeong SM, Kang JI, Ahn HJ, Kim HW, et al. Clinical Implications of Residual Urine in Korean Benign Prostatic Hyperplasia (BPH) Patients: A Prognostic Factor for BPH-Related Clinical Events. Int Neurourol J. 2010;14:238-44.

19. Schäfer W, Abrams P, Liao L, Mattiasson A, Pesce $F$, Spangberg $A$, et al. Good urodynamic practices: uroflowmetry, filling cystometry, and pressure-flow studies. Neurourol Urodyn. 2002;21:261-74.

20. Schleicher E, Wieland $\mathrm{OH}$. Evaluation of the Bradford method for protein determination in body fluids. J Clin Chem Clin Biochem. 1978;16:533-4.

21. Buege JA, Aust SD. Microsomal lipid peroxidation. Methods Enzymol. 1978;52:302-10.

22. Maklund S. Handbook of Methods for Oxygen radical Research. Boca Raton: CRC Press; 1985. pp.

23. Aebi H. Catalase in vitro. Methods Enzymol. 1984;105:121-6.

24. Azadzoi KM, Yalla SV, Siroky MB. Human bladder smooth muscle cell damage in disturbed oxygen tension. Urology. 2011;78:967.e9-15.

25. Callaghan CM, Schuler C, Leggett RE, Levin RM. Effect of severity and duration of bladder outlet obstruction on catalase and superoxide dismutase activity. Int $\mathrm{J}$ Urol. 2013;20:1130-5.

26. Malone L, Schuler C, Leggett RE, Levin RM. The effect of in vitro oxidative stress on the female rabbit bladder contractile response and antioxidant levels. ISRN Urol. 2013;2013:639685.

27. Fransen M, Nordgren M, Wang B, Apanasets 0 . Role of peroxisomes in ROS/RNS-metabolism: implications for human disease. Biochim Biophys Acta. 2012;1822:1363-73.

28. de Jongh R, Haenen GR, van Koeveringe GA, Dambros $M$, van Kerrebroeck PE. Lipid peroxidation product 4-hydroxynonenal contributes to bladder smooth muscle damage. Urology. 2008;71:974-8. 
29. de Jongh $R$, Haenen GR, van Koeveringe GA, Dambros M, De Mey JG, van Kerrebroeck PE. Oxidative stress reduces the muscarinic receptor function in the urinary bladder. Neurourol Urodyn. 2007;26:302-8.

30. Lin WY, Wu SB, Lin YP, Chang PJ, Levin RM, Wei YH. Reversing bladder outlet obstruction attenuates systemic and tissue oxidative stress. BJU Int. 2012;110:1208-13.

31. Fitzpatrick B, Schuler C, Leggett RE, Levin RM. Calcium effects on superoxide dismutase and catalase of the rabbit urinary bladder muscle and mucosa. Urol Int. 2012;88:107-11.

32. Kupelian V, Araujo AB, Wittert GA, McKinlay JB. Association of moderate to severe lower urinary tract symptoms with incident type 2 diabetes and heart disease. J Urol. 2015;193:581-6.

33. DiBello JR, loannou C, Rees J, Challacombe B, Maskell J, Choudhury $\mathrm{N}$, et al. Prevalence of metabolic syndrome and its components among men with and without clinical benign prostatic hyperplasia: a large, cross-sectional, UK epidemiological study. BJU Int. 2016;117:801-8.

34. Gratzke C, Bachmann A, Descazeaud A, Drake MJ, Madersbacher S, Mamoulakis C, et al. EAU Guidelines on the Assessment of Non-neurogenic Male Lower Urinary Tract Symptoms including Benign Prostatic Obstruction. Eur Urol. 2015;67:1099-109.

35. Cahn DB, Ross CP, Dubowitch EP, Persun ML, Ginsberg PC, Harkaway RC. Predicting Acute Urinary Retention in Patients with Elevated Post-Void Residuals. Curr Urol. 2015;8:79-83.

36. Crawford ED, Wilson SS, McConnell JD, Slawin KM, Lieber MC, Smith JA, et al. Baseline factors as predictors of clinical progression of benign prostatic hyperplasia in men treated with placebo. J Urol. 2006;175:1422-6; discussion 1426-7.

37. Rademakers KL, van Koeveringe GA, Oelke M; FORCE Research Group, Maastricht and Hannover. Ultrasound detrusor wall thickness measurement in combination with bladder capacity can safely detect detrusor underactivity in adult men. World J Urol. 2017;35:153-9.

38. Jeong SJ, Kim HJ, Lee YJ, Lee JK, Lee BK, Choo YM, et al. Prevalence and Clinical Features of Detrusor Underactivity among Elderly with Lower Urinary Tract Symptoms: A Comparison between Men and Women. Korean $\mathrm{J}$ Urol. 2012;53:342-8.

39. Abarbanel J, Marcus EL. Impaired detrusor contractility in community-dwelling elderly presenting with lower urinary tract symptoms. Urology. 2007;69:436-40.
40. Oelke M, Bachmann A, Descazeaud A, Emberton M, Gravas $S$, Michel $M C$, et al. EAU guidelines on the treatment and follow-up of non-neurogenic male lower urinary tract symptoms including benign prostatic obstruction. Eur Urol. 2013;64:118-40.

41. Erdem E, Leggett R, Dicks B, Kogan BA, Levin RM. Effect of bladder ischaemia/reperfusion on superoxide dismutase activity and contraction. BJU Int. 2005;96:169-74.

42. Yuan X, Wu S, Lin T, He D, Li X, Liu S, et al. Role of nitric oxide synthase in bladder pathologic remodeling and dysfunction resulting from partial outlet obstruction. Urology. 2011;77:1008.e1-8.

43. Oelke M, Höfner K, Jonas U, de la Rosette JJ, Ubbink DT, Wijkstra $H$. Diagnostic accuracy of noninvasive tests to evaluate bladder outlet obstruction in men: detrusor wall thickness, uroflowmetry, postvoid residual urine, and prostate volume. Eur Urol. 2007;52:827-34.

44. Güzel Ö, Aslan Y, Balcı M, Tuncel A, Keten T, Erkan A, et al. Can Bladder Wall Thickness Measurement Be Used for Detecting Bladder Outlet Obstruction? Urology. 2015;86:439-44.

45. Nickel JC. Long-term implications of medical therapy on benign prostatic hyperplasia end points. Urology. 1998;51(4A Suppl):50-7.

46. Ohwaki K, Endo F, Shimbo M, Fujisaki A, Hattori K. Comorbidities as predictors of incidental prostate cancer after Holmium laser enucleation of the prostate: diabetes and high-risk cancer. Aging Male. 2017;20:257-260.

47. Böcking A. [Pathology and epidemiology of prostatic cancer]. Radiologe. 1984;24:5-12.

48. Juan YS, Lin WY, Kalorin C, Kogan BA, Levin RM, Mannikarottu A. The effect of partial bladder outlet obstruction on carbonyl and nitrotyrosine distribution in rabbit bladder. Urology. 2007;70:1249-53. 